\title{
Joining of Silicon Nitride to Molybdenum under High Pressure
}

\author{
Katsuaki SUGANUMA, Mitsuji TAKAGI*, Yoshinari MIYAMOTO*, \\ Mitsue KOIZUMI**, Taira OKAMOTO* and Hirohiko NAKATA*** \\ National Defense Academy, 1-10-20, Hashirimizu, Yokosuka-shi, Kanagawa 239 \\ * The Institute of Scientific and Industrial Research, Osaka University, 8-1, Mihogaoka, Ibaraki-shi, Osaka 567 \\ ** Institute of Science and Technology, Ryukoku University, 67, Fukakusa-Tsukamoto-cho, Fushimi-ku, Kyoto-shi 612 \\ *** Japan Fine Ceramics Center, 2-4-1, Rokuno, Atsuta-ku, Nagoya-shi 456
}

\section{高圧力による窒化ケイ素とモリブデンの接合}

\author{
菅沼克昭・高木光司*・宮本欽生* ·小泉光恵** ·岡本 平*・仲田博彦*** \\ 防衛大学校, 239 横須賀市走水 1-10-20 \\ *大阪大学産業科学研究所, 567 茨木市美穂ケ丘 8-1 \\ ** 龍谷大学理工学研究所, 612 京都市伏見区深草塚本町 67
*** (財) ファインセセミックスセンター, 456 名古屋市熱田区六野 2-4-1
}

\begin{abstract}
Pressureless sintered silicon nitride was joined to molybdenum with metallic interlayers by hot-pressing and by hot-isostaticpressing. The interfacial strengths of niobium and molybdenum was $400 \mathrm{MPa}$. With increasing metal thickness, the residual stress in a joint increased resulting in a decreased strength. Lamination of molybdenum and tungsten layers reduced the residual stress. The highest tensile residual stress appeared at the corners of the square bond face joint. The magnitude of the residual stress depended on the dimension of the joint and increased with increasing size. When the side of the bond face was $20 \mathrm{~mm}$, the joint collapsed without any applied load. The joint with the molybdenum/tungsten laminate interlayer had the strength of $240 \mathrm{MPa}$ at $1173 \mathrm{~K}$ and was resistant to thermal cycles between $673 \mathrm{~K}$ and $1273 \mathrm{~K}$.
\end{abstract}

[Received June 14, 1988; Accepted July 22, 1988]

Key-words : Joining, Interface, Residual stress, Reaction, Interlayer, Silicon nitride, Heat resistance, Strength

\section{Introduction}

Silicon nitride is one of the candidates for the high temperature structural components used up to $1273 \mathrm{~K}$ with its remarkable features such as high strength, high modulus, good resistance to wear, light weight, etc. Such structural applications of ceramics requires a reliable joining method with a metallic component. Recently, Japanese companies have established the silicon nitride turbo-charger rotor for a car engine. "In that case, the blade made of silicon nitride was joined to a steel shaft with an active metal braze. Although brazings are one of the convenient methods to get a sound and tight joint, they cannot produce a heat resistant joint beyond about $773 \mathrm{~K}$ because both of the relatively low brazing temperature and poor oxidation resistance of the active metal braze. On the contrary, a solid-state bonding process is expected to produce a stable interface beyond $773 \mathrm{~K}$ if constituents and joining conditions are appropriately selected. In a solid-state bonding process it is quite important to achieve intimate contact at the interface. For this purpose, higher temperature, longer period and higher pressure are required for joining. However, reaction at the interface must be restricted to be moderate because a thick intermetallic compound layer, which is formed as the result of reaction, sometimes has large flaws inside and weakens a joint. ${ }^{21}$ Hence, the application of high pressure is the most beneficial for solid-state bonding.

The aim of the present work was to examine the possibilities of a solid-state joining process for the combination of silicon nitride and molybdenum with refractory metal interlayers for the high temperature applications beyond $1000 \mathrm{~K}$.

\section{Experimental}

Pressureless sintered silicon nitride used in this study contained alumina and yttria as sintering additives. Niobium and molybdenum were selected as the first interlayer which formed the interfaces with silicon nitride. The second interlayer, i.e. tungsten, which has the smallest thermal expansion coefficient among all pure metals, was adopted to reduce residual stress when silicon nitride was joined to a molybdenum block. Such a laminate interlayer structure has been known to give one of the effective joining constructions for the joint with large thermal expansion mismatch. ${ }^{3)}$ All metals were approx- 
imately $99.5 \%$ pure.

Two types of joint were prepared. One was the silicon nitride/thin metal/silicon nitride joint for measuring interfacial strengths between silicon nitride and the metals and the other was the silicon nitride/molybdenum joint with interlayers for evaluating the overall strength including residual stress effect. The constructions and dimensions of the joints are illustrated in Fig. 1. To examine the size effect on residual stress, the thickness of the second interlayer and the length of the side of the bond face were varied.

Joinings were carried out using hot-isostaticpressing (HIP) and hot-pressing (HP). A glass capsule method was adopted for HIP. ${ }^{4)}$ The diagrams of temperature and pressure are schematically illustrated in Fig. 2. The temperature
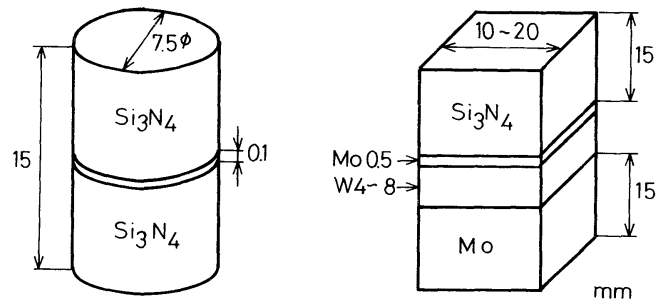

Fig. 1. Schematics of silicon nitride/metal joints. Left : A joint for the evaluation of interfacial strength,

Right: A joint for measuring residual stress and strength of silicon nitride/molybdenum joint with an interlayer.

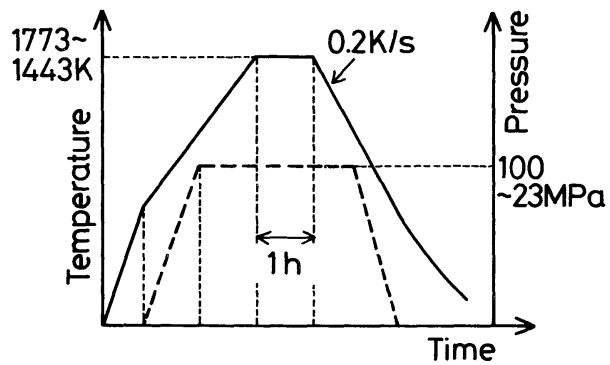

( A)

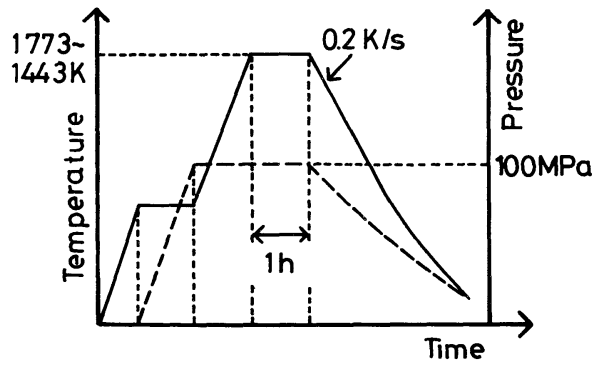

(B)

Fig. 2. Diagrams of temperature and pressure for (A) HP joining and (B) HIP joining. range was between 1443-1773 $\mathrm{K}$ for both joinings and the pressure was $100 \mathrm{MPa}$ for HIP and $23 \mathrm{MPa}$ and $100 \mathrm{MPa}$ for $\mathrm{HP}$. The joining period was fixed to be $1 \mathrm{~h}$. HP was carried out in a vacuum of $3 \times 10^{-5}$ Torr.

Three-point and four-point bending tests were performed for the evaluation of interfacial strengths and of joint strength with a large residual stress, respectively. The bend bars had a $2 \mathrm{~mm} \times 2 \mathrm{~mm}$ cross section and the cross-head speed was $0.5 \mathrm{~mm} / \mathrm{min}$ for both tests. The span for the three-point bending test was $10.2 \mathrm{~mm}$. The upper and the lower spans were $10 \mathrm{~mm}$ and $30 \mathrm{~mm}$, respectively, for the four-point bending test. The strength of the joint at $1173 \mathrm{~K}$ were measured in argon steam. Some of the joints were subjected to thermal cycle between 673 and $1273 \mathrm{~K}$ in a vacuum of $1 \times 10^{-5}$ Torr. The heating and cooling rates were $1 \mathrm{~K} / \mathrm{s}$. The joints were held at $1273 \mathrm{~K}$ for $10 \mathrm{~min}$. The maximum number of cycles was 100 . The strength shown here are average data of four specimens.

Because of elastic constant mismatch between ceramics and metals, the deviation from the stress distribution derived by the analytical equation near interface and near free surface have to be taken into consideration for the accurate evaluation of strength. Some of the present authors have already reported this effect evaluated by a finite element method. ${ }^{5)}$ However, because this effect involves the underestimation within $10 \%$, which is not so serious, all strengths shown here are the apparent values derived from the analytical equation assuming that the joints are elastically uniform.

The residual tensile stress acting perpendicularly to the interface on the joint, which is the most harmful stress in a ceramic/metal joint, was measured by a strain gauge method, ${ }^{5}$ varying length of the side of the bond face, thickness of the tungsten interlayer.

\section{Results and discussion}

\section{1 Interfacial structure and strength}

Figure 3 shows the representative interfacial microstructure. Thin silicide layers were formed in the metals. The silicide layers grew as increasing joining temperature, which is shown in Fig. 4. The growth rates of the silicide layers by HIP were larger than those by HP. When the thickness was beyond $2-3 \mu \mathrm{m}$, cracking in the silicide layers was recognized apparently as seen in Fig. 3.

The silicides were determined to be mainly $\mathrm{Nb}_{5} \mathrm{Si}_{3}$ and $\mathrm{MO}_{5} \mathrm{Si}_{3}$ with X-ray diffraction analysis of the fracture surfaces, respectively. Their formations did not change between different join- 


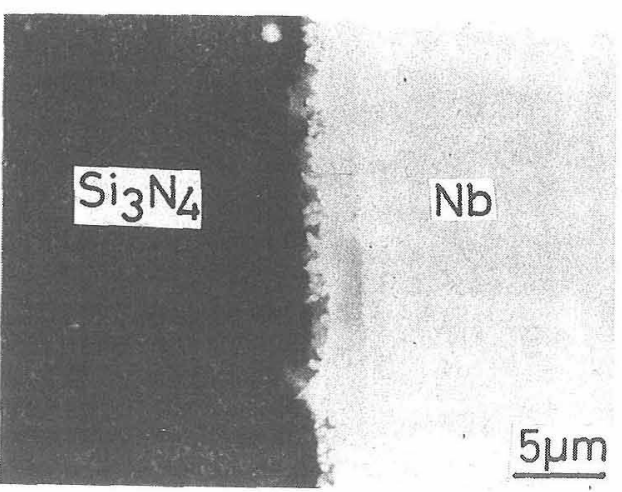

Fig. 3. Typical interfacial microstructure by SEM. Silicon nitride/niobium interface reacted at $1673 \mathrm{~K}$ for $1 \mathrm{~h}$ by HIP. A crack is observed in the silicide layer.

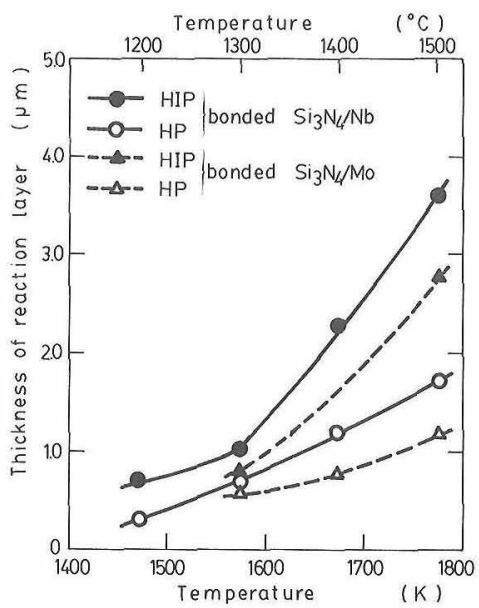

Fig. 4. Thickness of silicide layers as a function of reaction temperature.

ing methods. The difference in growth rate was not concerned with the magnitude of pressure because the pressure was controlled at $100 \mathrm{MPa}$ for both cases. The difference in joining atmosphere seems to play an important role. That in HIP is a closed one and that in HP is a continuously evacuated one. Since the formation of silicides is accompanied with release of nitrogen, the continuous evacuation might promote the reaction. The tendency was, however, just the reverse. A detail examination on this effect is now undergoing.

Figures 5 and 6 summarize the interfacial strengths as a function of joining temperature. All the strength except that of the silicon nitride/niobium joint by HIPing increased monotonously as increasing joining temperature. The silicon nitride/niobium joint by HIPing had the maximum value at $1673 \mathrm{~K}$ and decreased strength beyond $1673 \mathrm{~K}$ slightly. This degradation in strength at higher joining temperature seems to be

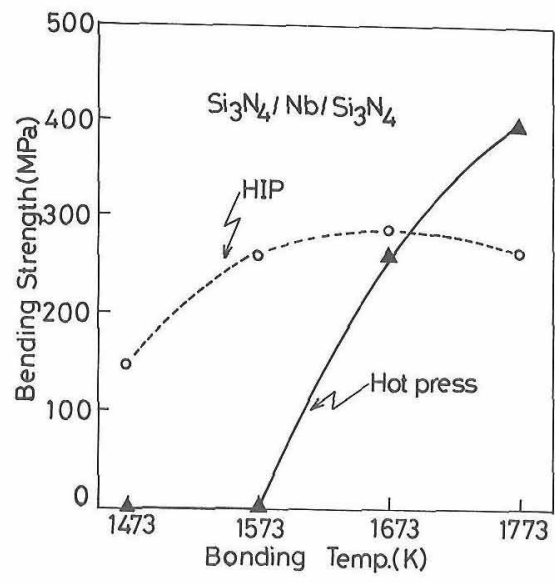

Fig. 5. Bending strength of the silicon nitride/ niobium interface as a function of reaction temperature.

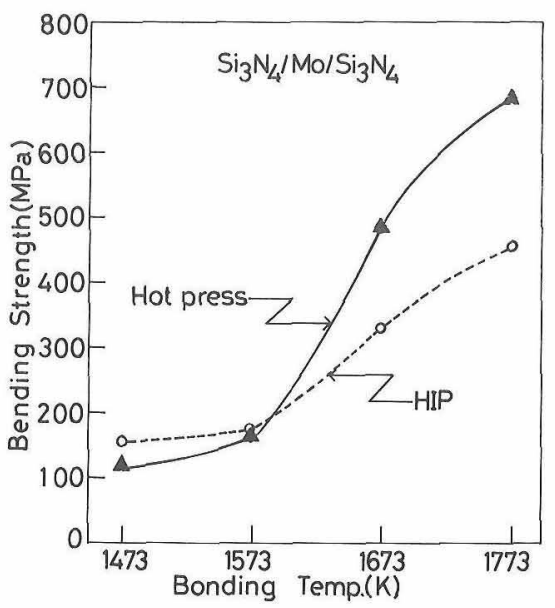

Fig. 6. Bending strength of the silicon nitride/molybdenum interface as a function of reaction temperature.

caused by the growth of the silicide layer. The silicide thicker than approximately $3 \mu \mathrm{m}$ had a lot of cracks inside. Those cracks seem to weaken the joint.

Although the strengths of both the joints by HIP were higher than those by HP in lower temperature range, the latter became over the former in the higher temperature range. This trend is just the same as that observed in the growth of the silicide layer as seen in Fig. 4. Such a growth of intermetallic reaction layers is known to weaken a strength of joints. ${ }^{2)}$ In the present cases, the fact that the growth of the reaction layer under a HIP treatment were faster than those by HP caused these differences in strength.

\subsection{Residual stress}

Silicon nitride could not be joined to a block of molybdenum with or without a single interlayer of 


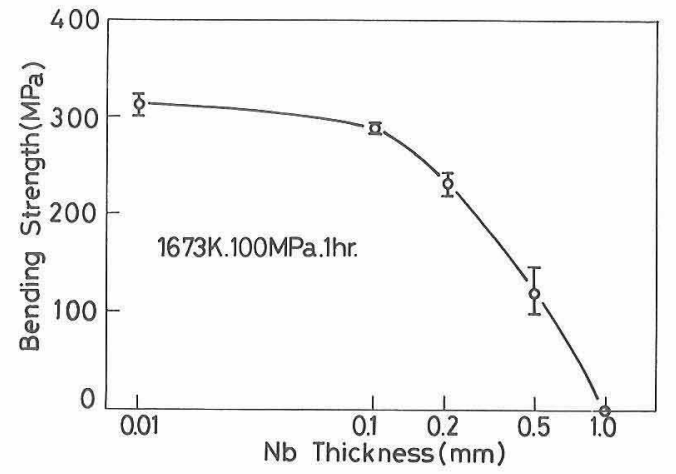

Fig. 7. Bending strength of the silicon nitride/ niobium joint as a function of thickness of niobium layer.

niobium. As increasing thickness of the metal, residual stress increases and, finally, the joint will be broken without any applied load. Figure 7 shows the effect of thickness of niobium layer on the strength of the silicon nitride/niobium joint. The strength decreased when the thickness was beyond $0.1 \mathrm{~mm}$. The joint with a $1 \mathrm{~mm}$ niobium layer fractured just after joining as shown in Fig. 8. The fracture mode was a "concave/convex" type which is sometimes observed in joints with large thermal expansion mismatch. ${ }^{7)}$

The adoption of the second layer, i. e. tungsten, was very effective to produce a sound joint. However, HP joining sometime brought about a plastic deformation of the metals during joining

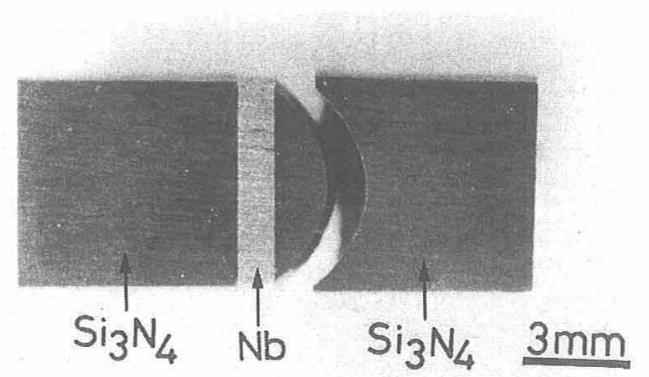

Fig. 8. Fracture of silicon nitride/1 $\mathrm{mm}$ thick niobium joint just after joining by HIP. Cracks are observed on the both side of the niobium layer and the right side one grew without any applied load.

even in a low pressure of $23 \mathrm{MPa}$ as shown in Fig. 9. Therefore, HIP was performed hereafter. From the view point of the interfacial strength with silicon nitride with HIP, molybdenum could form a stronger interface. Finally, the interlayer was fixed as a molybdenum/tungsten laminate. It was possible to join silicon nitride to a molybdenum block with the molybdenum/tungsten laminate layer. Tungsten has smaller thermal expansion coefficient and is hard. This interlayer structure is known as one of the effective interlayers with large thermal expansion mismatch. ${ }^{3)}$

Figure 10 shows the distribution of the tensile residual stress acting perpendicularly to the inter-
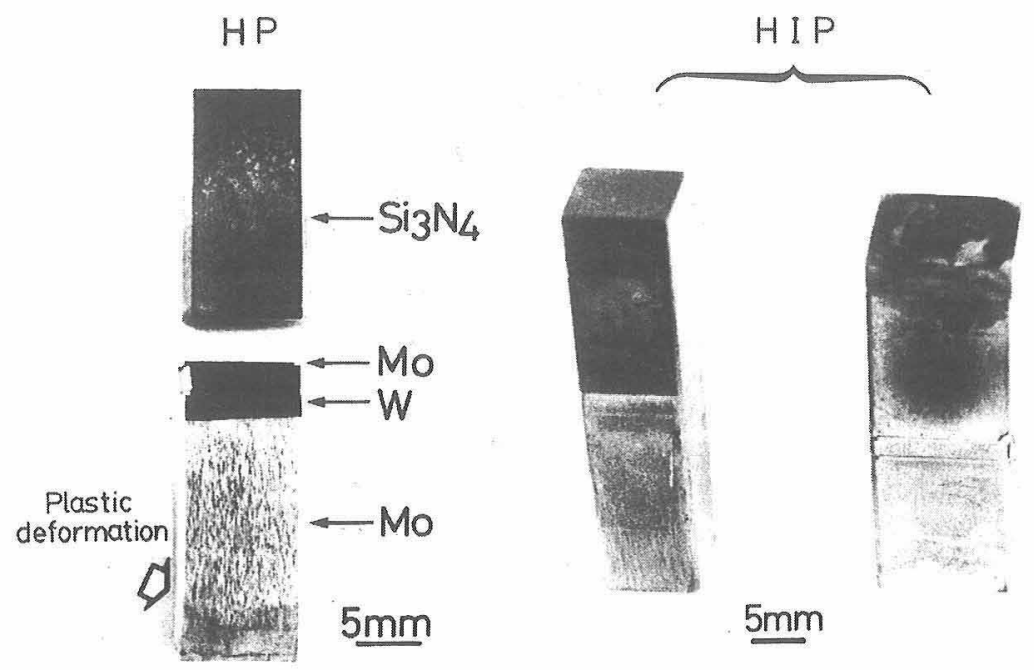

Fig. 9. Silicon nitride/molybdenum joints with the molybdenum/tungsten laminate interlayer by HP and by HIP. The HP joining induced large plastic deformation of molybdenum in spite of lower pressure, $23 \mathrm{MPa}$, than that for HIP, $100 \mathrm{MPa}$. 


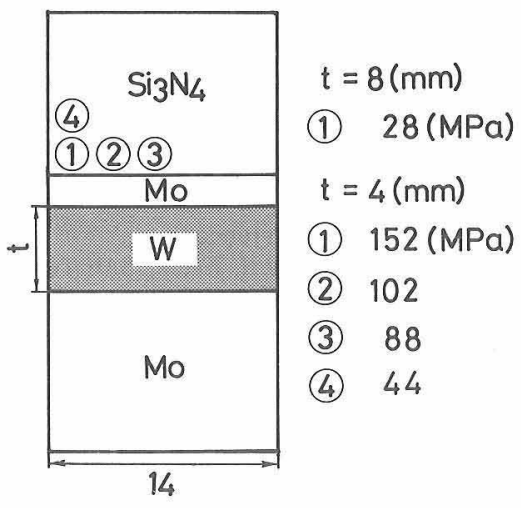

Fig. 10. Tensile residual stress perpendicular to the interface on the silicon nitride surface measured by the strain gauge method.

face. The residual stress increased as closing both toward the corner and toward the interface, which coincided with the previous work. ${ }^{61,8)}$ It was drastically reduced with increasing the thickness of the tungsten layer from $4 \mathrm{~mm}$ to $8 \mathrm{~mm}$. Figure 11 shows the effect of the size of the bond face on the magnitude of residual stress. The residual stress increased with increasing the size and, finally, beyond $20 \mathrm{~mm}$ in length of the side cracking was rcognized in the silicon nitride. This size dependence of residual stress is very important because joints with a large bond face might not be obtained even such a laminate interlayer. Further modification will be required.

\section{3 Heat resistance}

Table 1 summarizes the heat resistance of the silicon nitride/molybdenum joint with a $0.5 \mathrm{~mm}$ molybdenum/8 mm tungsten laminate interlayer. The joint had a fairly good strength at room

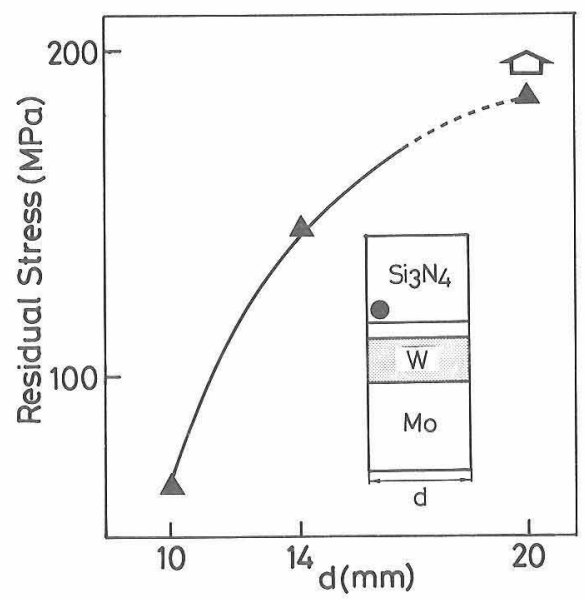

Fig. 11. Tensile residual stress perpendicular to the interface on the silicon nitride surface as a function of length of the side. The joint having a side $20 \mathrm{~mm}$ in length had cracks in silicon nitride just after joining.
Table 1. Four-point bending strengths of the silicon nitride/molybdenum joint with laminate interlayer $(\mathrm{MPa})$.

\begin{tabular}{l|c|c}
\hline Condition & strength & Fracture position \\
\hline Room temperature & 370 & in silicon nitride \\
\hline At $1273 \mathrm{~K}$ & 240 & along the interface \\
\hline $\begin{array}{l}\text { After thermal cycle } \\
\text { Room temperature }\end{array}$ & 140 & along the interface \\
\hline
\end{tabular}

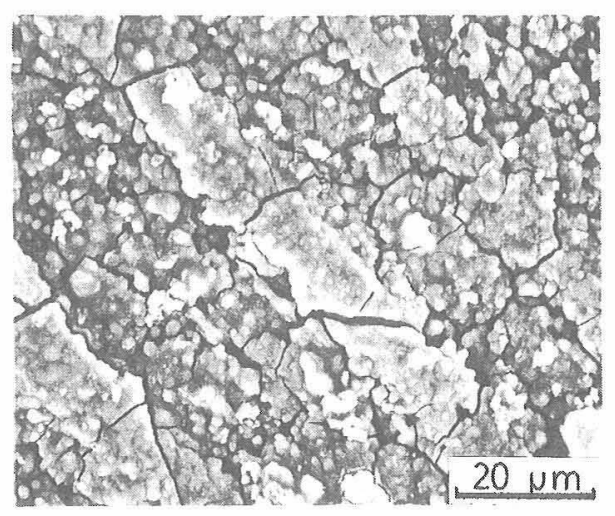

Fig. 12. Fracture surface of the metals side of the silicon nitride/molybdenum joint with the laminate interlayer after being subjected to 100 thermal cycles (SEM).

temperature and, even at $1173 \mathrm{~K}$, kept the strength level above $200 \mathrm{MPa}$. The joint fractured in silicon nitride near the interface at room temperature. This fact indicates that the presence of residual stress reduces the strength of the joint. At $1173 \mathrm{~K}$ the interface became weak slightly and, hence, the fracture proceeded almost along the interface between silicon nitride and molybdenum. The thermal cycle between 673 and $1273 \mathrm{~K}$ reduced strength at room temperature. But the joint still kept the strength level beyond $100 \mathrm{MPa}$ after 100 cycles. The joint subjected to thermal cycle fractured along the interface. Microstructural evidences indicated the formation of microcracks in the reaction layer formed between silicon nitride and molybdenum (Fig.12). The formation of microcracks seems to be responsible for the reduction of the strength.

\section{Conclusion}

Silicon nitride was joined to itself with niobium or molybdenum layers and to a block of molybdenum with the laminates of niobium/tungsten and of molybdenum/tungsten in solid-state by using hot-pressing and by hot-isostatic-pressing. Sili- 
cide layers were mainly formed at the interfaces in both cases. The interfacial strengths of silicon nitride and two metals were beyond $400 \mathrm{MPa}$ by bending test and enough for engineering applications. However, only the molybdenum/tungsten laminate could produce the stable joint of silicon nitride and molybdenum. The joint with the laminate of molybdenum/tungsten had a good strength and maintained the strength level beyond $200 \mathrm{MPa}$ at $1173 \mathrm{~K}$. Although the joint decreased the strength by thermal cycle between 673 and $1273 \mathrm{~K}$, it could keep the level beyond $100 \mathrm{MPa}$ for the prolonged cycles. Residual stress became larger as increasing the size of the joint and, finally, the joint fractured without any applied load. The size limit in the present case was the square face with approximately $15 \mathrm{~mm}$ in side length. Larger joints will require a further modification of the joining constructions, i. e. interlayer structures.
Acknowledgments The present work was partly supported by the Joint Research Program between University and Industry (Sumitomo Electric Industries, Co., Ltd.), promoted by the Ministry of Education, Science, and Culture. The authors are grateful to Dr. M. Miyake of Sumitomo for helpful discussions and encouragement.

\section{References}

1) M. Itoh, N. Ishida and N. Katoh, SAE Technical paper series, 880704 (1988).

2) M. G. Nicholas and D. A. Mortimer, Mater. Sci. Tech nol., 1, 657-65 (1985).

3) K. Suganuma, T. Okamoto, M. Koizumi and M. Shimada, J. Am. Ceram. Soc., 67, C 256-57 (1984).

4) ibid., High Temperature Science, 20, 127-39 (1985).

5) ibid., J. Nucl. Mater., 133 \& 134, 773-77 (1985).

6) K. Suganuma, T. Okamoto, M. Koizumi and K. Kamachi, J. Mater. Sci., 22, 3561-65 (1987).

7) K. Suganuma, T. Okamoto, Y. Miyamoto, M. Shimada and M. Koizumi, Mater. Sci. Technol., 2, 1156-61 (1986).

8) A. Kohno, T. Yamada and S. Hioki, J. Japan Inst. Metals, 49, 876-83 (1985). 